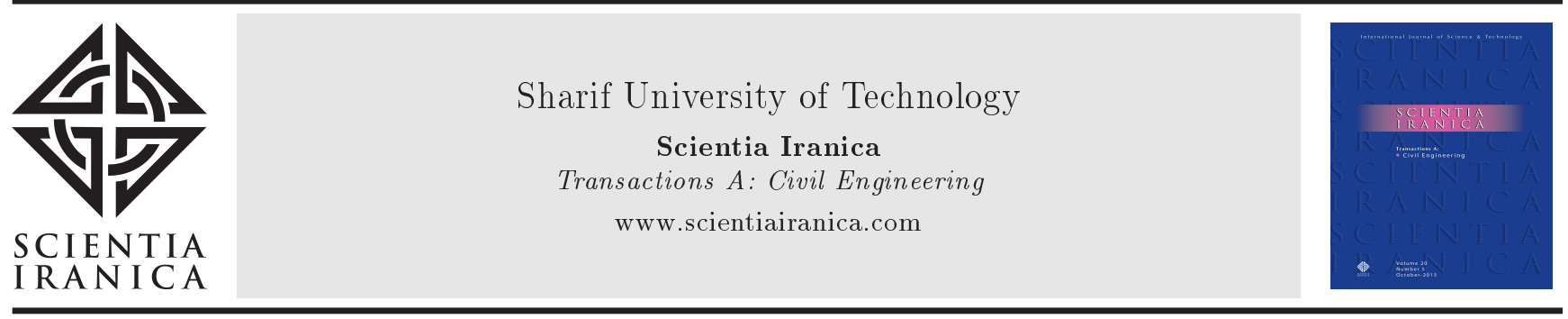

\title{
Polynomial models controlling strength of zeolite-cement-sand mixtures
}

\author{
H. Mola-Abasi* and I. Shooshpasha \\ Department of Civil Engineering, Babol University of Technology (BUT), Babol, Iran. \\ Received 14 September 2015; received in revised form 19 January 2016; accepted 30 January 2016
}

\author{
KEYWORDS \\ Zeolite; \\ Cemented sand; \\ Unconfined \\ compressive strength; \\ Polynomial; \\ Sensitivity analysis.
}

\begin{abstract}
The improvement of local soils with cement and zeolite can provide great benefits, including strengthening slopes in slope stability problems and stabilizing problematic soils to prevent soil liquefaction. Recently, dosage methodologies have been developed for improved soils based on a rational criterion as it exists in concrete technology. The present study aims to quantify the influence of the amount of cement, zeolite, porosity, and curing time in the evaluation of Unconfined Compressive Strength (UCS) of zeolitecemented sand mixtures. A program of unconfined compression tests considering different voids ratios, cement contents, zeolite contents, and curing times was performed in this paper. The results show that UCS values of samples substantially increase with increasing zeolite content to an optimum value of $30 \%$ after 28 days of curing time. The rate of improvement is approximately between 20 to $80 \%$ and $20 \%$ to $60 \%$ for 28 and 90 days curing times, respectively. Moreover, the polynomial models are shown to be the appropriate ones to estimate UCS values of zeolite-cemented mixtures. Additionally, the sensitivity analysis reveals the influence of parameters and the contribution of each coefficient to the polynomial model. Cement and zeolite contents are related more strongly among relative density and curing time.
\end{abstract}

C 2017 Sharif University of Technology. All rights reserved.

\section{Introduction}

For many years, soil stabilization with cement has been a ground improvement technique for some engineering applications such as construction of stabilized bases under pavements, canal lining, and engineered fills. This reliable and simple soil improvement technique can provide great advantages including increasing shear strength parameters and avoiding the use of borrowing materials from elsewhere. The compressive strength of artificially cemented soils has been studied by many researchers [1-14]. On the other hand, using additive fiber, glass, fly ash, silica fume, and nano particle in ce-

*. Corresponding author. Fax: +98 1132331701 E-mail addresses: hma@stu.nit.ac.ir (H. Mola-Abasi); shooshpasha@nit.ac.ir (I. Shooshpasha) ment stabilization industry has several advantages [1520]. Natural zeolite is one of these mineral materials. There are few studies about the effect of natural zeolite as an additive material on the cemented sand. Natural zeolite, an extender, has been investigated for use as cement and concrete improver by some researchers [21-22]. In this study, the use of a natural zeolite additive, as a potential improver of cemented sand, is investigated. Natural zeolite contains large quantities of reactive $\mathrm{SiO}_{2}$ and $\mathrm{Al}_{2} \mathrm{O}_{3}$ [21]. Similar to other pozzolanic materials, zeolite substitution can improve the strength of cement by pozzolanic reaction with $\mathrm{Ca}(\mathrm{OH})_{2}$, can prevent undesirable expansion due to alkali-aggregate reaction, reduce the porosity of the blended cement paste, and improve the interfacial microstructure properties between the blended cement pastes $[21,23,24]$. It has been observed that pozzolanic 
activity of natural zeolite is higher than that of fly ash but lower than that of silica fume [21]. It was concluded that the clinoptilolite blend decreases the specific gravity of cements [25].

There are several investigations about the relationship between Unconfined Compressive Strength (UCS) and voids/cement ratio of cemented sand $[1,6,7]$. However, the existing equations based on voids/cement ratio cannot properly estimate UCS values of zeolitecemented sand mixtures. Therefore, in this paper, polynomial models are used for predicting them.

This study aims to investigate the effects of zeolite, cement, curing time, and porosity on the strength of zeolite-cemented sand mixtures. In this paper, first, experimental program was presented and discussed in detail. Then, polynomial models for predicting UCS values were defined. Finally, sensitivity analyses of zeolite-cemented sand mixtures were described.

\section{Experimental program}

Several unconfined compression tests were performed and the results are considered in this paper. Cement content, replacement of cement by zeolite, relative density, and curing time are the variables measured in the testing program. Table 1 shows the variables considered in sample preparation and testing. The positive effects of zeolite on the strength of cemented sand requires the curing time due to the pozzolanic reactions. So, the curing times of 28 and 90 days are selected. The experimental program is carried out in two parts. First, the geotechnical properties of the sand, zeolite, and cement were characterized. Then, a series of unconfined compression tests were carried out and discussed.

\subsection{Materials}

The materials in this study include Babolsar sand, Portland cement type-II, and natural clinoptilolite kind of zeolite.

\subsubsection{Sand}

The sandy soil used in the present study was obtained from the shores of the Caspian Sea (from the city of Babolsar, northern Iran). The sand was classified as poorly graded sand (SP) according to the Unified Soil Classification System with angular particle shape and specific gravity of the solids 2.74. The grain size is purely fine sand with mean effective diameter $\left(D_{50}\right)$, uniformity, and curvature coefficients of $0.24,1.75$, and $0.89 \mathrm{~mm}$, respectively. In addition, the minimum and maximum unit weight values are 14.9 and $17.7 \mathrm{kN} / \mathrm{m}^{3}$, respectively [26,27]. The grain-size distribution curves of sand are presented in Figure 1.

\subsubsection{Cement}

Portland cement type II was applied in this research. Specific surface, initial setting time, and the specific gravity of the cement grains values are $>3000\left(\mathrm{~cm}^{2} / \mathrm{g}\right)$, $>75(\mathrm{~min})$, and 3.11 , respectively.

\subsubsection{Zeolite}

The natural clinoptilolite zeolites with particles smaller than $75 \mu \mathrm{m}$ (No. 200 sieve) obtained from an area near Aftar city in Semnan province of Iran were used in the tests. The used zeolite is non-plastic and classified as silt (ML) according to the Unified Soil Classification System with specific gravity of 2.2 .

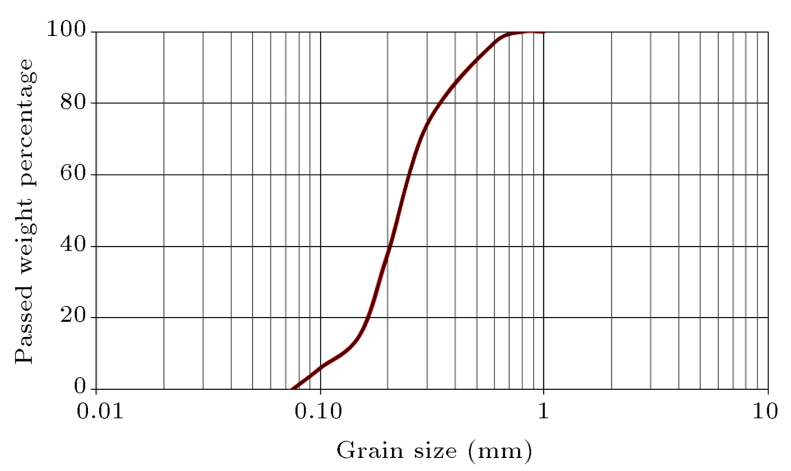

Figure 1. Grain-size distribution of sand.

Table 1. Description of variables in the present study.

\begin{tabular}{ccl}
\hline Variables & No. of levels & Description of samples \\
\hline Soil type & 1 & Poorly-graded sand from Babolsar City (shores of Caspian Sea) \\
Cement agent & 1 & Portland cement (type II) \\
Cement content & 4 & $2,4,6$, and $8 \%$ dry unit weight of base soil \\
Type of zeolite & 1 & Natural cilnopiolite zeolite \\
Zeolite content & 6 & $0,10,30,50,70$, and $90 \%$ of cement \\
Relative density & 3 & 50,70, and $85 \%$ \\
Water content & 1 & $10 \%$ weight of base soil \\
Sample size & 1 & 38 mm diameter and 76 mm height, compacted in three layers \\
Curing condition & 3 & Cured for 7,28, and 90 days in humid room \\
Total number of test & 216 & \\
\hline
\end{tabular}




\subsection{Sample preparation and test process}

For the unconfined compression tests, cylindrical specimens, $38 \mathrm{~mm}$ in diameter and $76 \mathrm{~mm}$ in height, were used. According to Eq. (1), the target dry unit weight, $\gamma_{d}$, was calculated for a given void's ratio $(e)$ which relates to Dr of sand $(85,70$, and $50 \%)$ :

$$
\gamma_{d}=\frac{G_{s} \gamma_{w}}{1+e}
$$

Because the specific gravity of the cement grains is 3.11 , sand is 2.74 , and zeolite is 2.2 , a composite specific gravity $\left(G_{s}\right)$ based on the cement, sand, and zeolite percentages in the specimen was used for the calculation of voids ratio and porosity. Sand, cement, and zeolite (based on Table 1) were mixed uniformly, then tap water ( $10 \%$ by dry weight of soil) was added continuously to the mixture. In order to reach the specified dry unit weight, each mixture was compacted in three layers based on the under-compaction method. The top of each layer was slightly scarified. The time used to prepare, mix, and compact was always less than 1 hour for all of the samples. It should be noted that using zeolite increases the initial setting time of cement. In order to determine moisture content, small portions of the mixtures were taken. The specimens were placed in plastic bags and cured in a humid room at $24^{\circ} \mathrm{C}$ and relative humidity of above $90 \%$ for 7,28 , and 90 days. The unconfined compression test is one of the major and rapid laboratory tests that can be used to evaluate the effects of the zeolite content, porosity, cement content, and curing time on the mechanical strength of the zeolite-cement-sand mixtures. Totally, 216 unconfined compression tests were performed in accordance with ASTM D-2166 [28].

\section{Modelling using polynomial models}

Over the last few years, the polynomial models have been applied to many geotechnical engineering problems and demonstrated some degrees of success. In this field, Kalantary et al. [29], Ardalan et al. [30], Mola-Abasi et al. [31], and Kordnaeij et al. [32] applied polynomial models to predict undrain shear strength of clays, pile bearing capacity, liquefaction induced lateral displacement, shear wave velocity, shear wave velocity, and recompression index of consolidation based on geotechnical soil properties, respectively. Thus, this approach can be used in empirical correlation of zeolitecement-sand mixture's UCS.

The basic assumption is that a pair of input parameters can be connected through a polynomial function to outputs. The task is to find a function, $\hat{f}$, that can be approximated to an observed function $f$ in order to produce the value of the output, $\hat{y}$, for a given value of the input vector, $X=\left(x_{1}, x_{2}, x_{3}, \ldots, x_{n}\right)$, such that the difference between $\hat{y}$ and $y$ is minimum.
Therefore, for a given $M$ observations of multi-input, single output data pairs are obtained as follows:

$$
y_{i}=f\left(x_{i 1}, x_{i 2}, x_{i 3}, \ldots, x_{i n}\right) \text { where } i=1,2, \ldots, M .
$$

It is possible to use a polynomial function to predict the output values, $\hat{y}_{i}$, for any given input vector, $X=$ $\left(x_{i 1}, x_{i 2}, x_{i 3}, \ldots, x_{i n}\right)$, such that:

$$
\hat{y}_{i}=\hat{f}\left(x_{i 1}, x_{i 2}, x_{i 3}, \ldots, x_{i n}\right) \text { where } i=1,2, \ldots, M \text {. }
$$

The challenge is to define a polynomial function, such that the square of the differences between the observed output and predicted one are minimum:

$$
\sum_{i=1}^{M}\left[\hat{f}\left(x_{i 1}, x_{i 2}, x_{i 3}, \ldots, x_{i}\right)-y_{i}\right]^{2} \rightarrow \min .
$$

The general connection between input and output variables can be expressed by a discrete form of the Volterra functional series, known as KolmogorovGabor polynomial [33]. Hence:

$$
\begin{aligned}
y= & a_{0}+\sum_{i=1}^{n} a_{i} x_{i}+\sum_{i=1}^{n} \sum_{j=1}^{n} a_{i j} x_{i} x_{j} \\
& +\sum_{i=1}^{n} \sum_{j=1}^{n} \sum_{k=1}^{n} a_{i j k} x_{i} x_{j} x_{k}+\ldots
\end{aligned}
$$

This mathematical description can be represented by a system of quadratic polynomials consisting of only two variables in the form:

$$
\begin{aligned}
\hat{y}= & G\left(x_{i}, x_{j}\right)=a_{0}+a_{1} x_{i}+a_{2} x_{j}+a_{3} x_{i} x_{j} \\
& +a_{4} x_{i}^{2}+a_{5} x_{j}^{2} .
\end{aligned}
$$

The coefficients $a_{i}$ in Eq. (6) are calculated using regression analysis, so that the difference between the observed output, $y$, and the calculated one, $\hat{y}$, for each pair of $x_{i}$ and $x_{j}$ as input variables is minimum:

$$
E=\frac{1}{M} \sum_{i=1}^{M}\left(y_{i}-G_{i}\right)^{2} \rightarrow \min .
$$

Using the quadratic expression in Eq. (6) for each of the $M$ rows, the following matrix can be obtained:

$$
A a=Y,
$$

where $a$ is the vector of unknown coefficients for the quadratic polynomial function in Eq. (6), and $Y$ is the vector of output values from observation. Then, $A$ takes the form:

$$
A=\left[\begin{array}{cccccc}
1 & x_{1 p} & x_{1 q} & x_{1 p} x_{1 q} & x_{1 p}^{2} & x_{1 q}^{2} \\
1 & x_{2 p} & x_{2 q} & x_{2 p} x_{2 q} & x_{2 p}^{2} & x_{2 q}^{2} \\
\cdot & \cdot & \cdot & \cdot & \cdot & \cdot \\
1 & x_{M p} & x_{M q} & x_{M p} x_{M q} & x_{M p}^{2} & x_{M q}^{2}
\end{array}\right]_{M \times 6}
$$


A least-squares optimization approach for multiple regression analysis leads to the solution of the normal equations:

$$
a=\left(A^{T} A\right)^{-1} A^{T} Y .
$$

The vector is given the best-fit coefficients for Eq. (6) for the whole set of $M$ data triplets.

\section{Results and discussion}

Figure 2 shows the stress-strain curves of specimens, stabilized with cement contents of 4 and $8 \%$ and different zeolite contents (for $\mathrm{Dr}=85 \%$ ) cured in 7 and 90 days. It can be observed that the maximum axial stress increases considerably and the corresponding strain decreases due to cement stabilization. However, the strain corresponding to the maximum axial stress increases with increasing zeolite content. In other words, utilizing zeolite in cemented sand increases strain at failure and reduces brittle behavior. Since the main purpose of this paper is estimation of the UCS values, less attention has been paid to the study of strain and failure.

\subsection{Effects of cement and zeolite contents}

Results of unconfined compression tests for samples with cement contents of 2, 4, 6, and $8 \%$ and zeolite
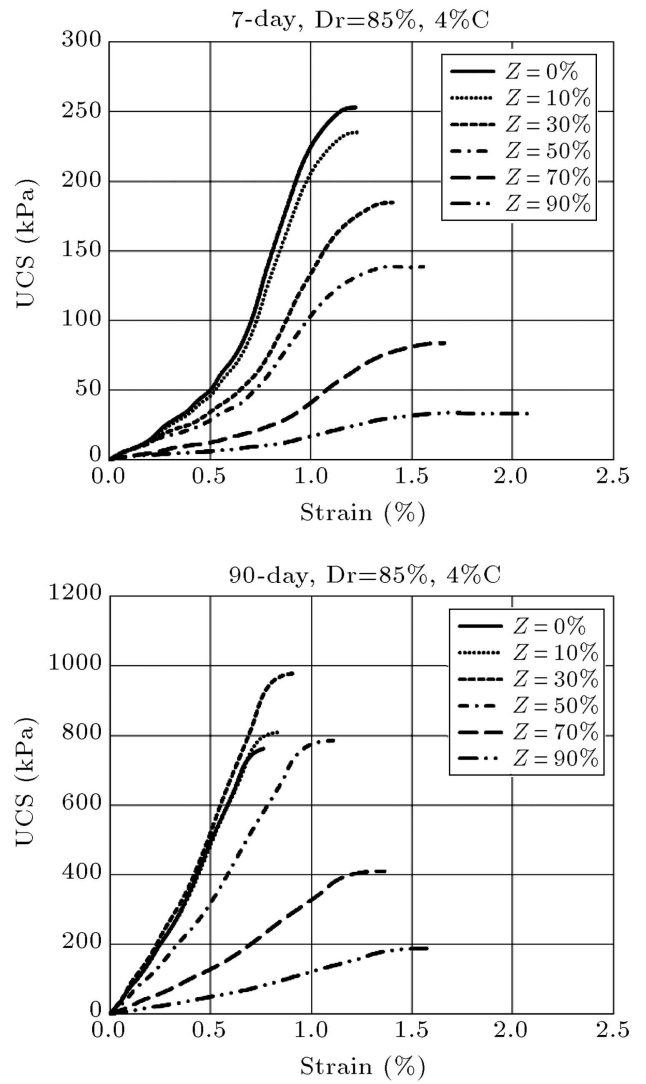

contents of $0,10,30,50,70$, and $90 \%$ cured in 7 to 90 days are indicated in Figure 3.

It is seen that for a given Dr and zeolite content, UCS value increases with increasing cement content after 28 days. By adding zeolite to cemented sand, UCS values of mixtures increase to a peak point, and then reduce. It is noteworthy that zeolite is composed of amorphous minerals without definable crystalline structure and both cement and zeolite are predominantly formed of silica and alumina, chemically. Therefore, pozzolanic reactions, time-dependent chemical reactions between cement and zeolite particles, were occurred after 28 days of curing. Such reactions take place because silica and alumina within the zeolite structure react with water and cement to form calcium silicate hydrate and calcium aluminate hydrate gels, which consequently crystallize to hold the structure together. Adding zeolite into the mixture increases the amounts of alumina and silica, grows reactions with cement, and subsequently increases mixture strength. Because of cement content reduction, the amounts of calcium silicate hydrate and calcium aluminate hydrate gels decrease with increasing zeolite contents more than $30 \%$. Therefore, the results show that the maximum value of UCS for mixtures occurs at the zeolite content of $30 \%$. Figure 4 shows the increase rate ([UCS zeolite cemented sand $^{-}$ $\left.\mathrm{UCS}_{\text {cemented sand }}\right] / \mathrm{UCS}_{\text {cemented sand }}$ ) of UCS values for
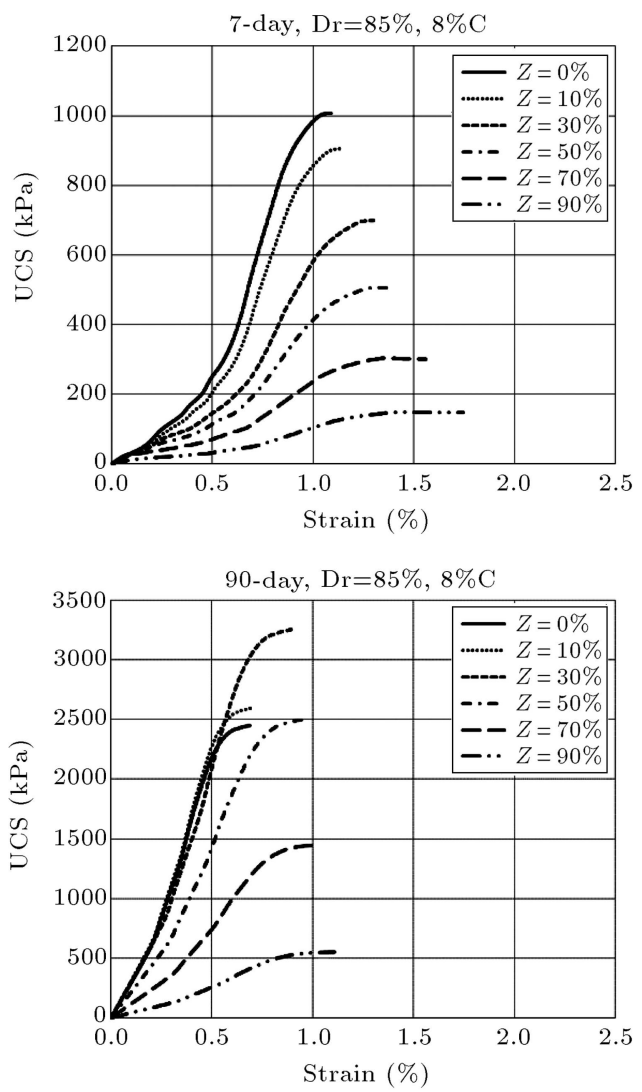

Figure 2. Stress-strain behavior of zeolite cemented sand. 

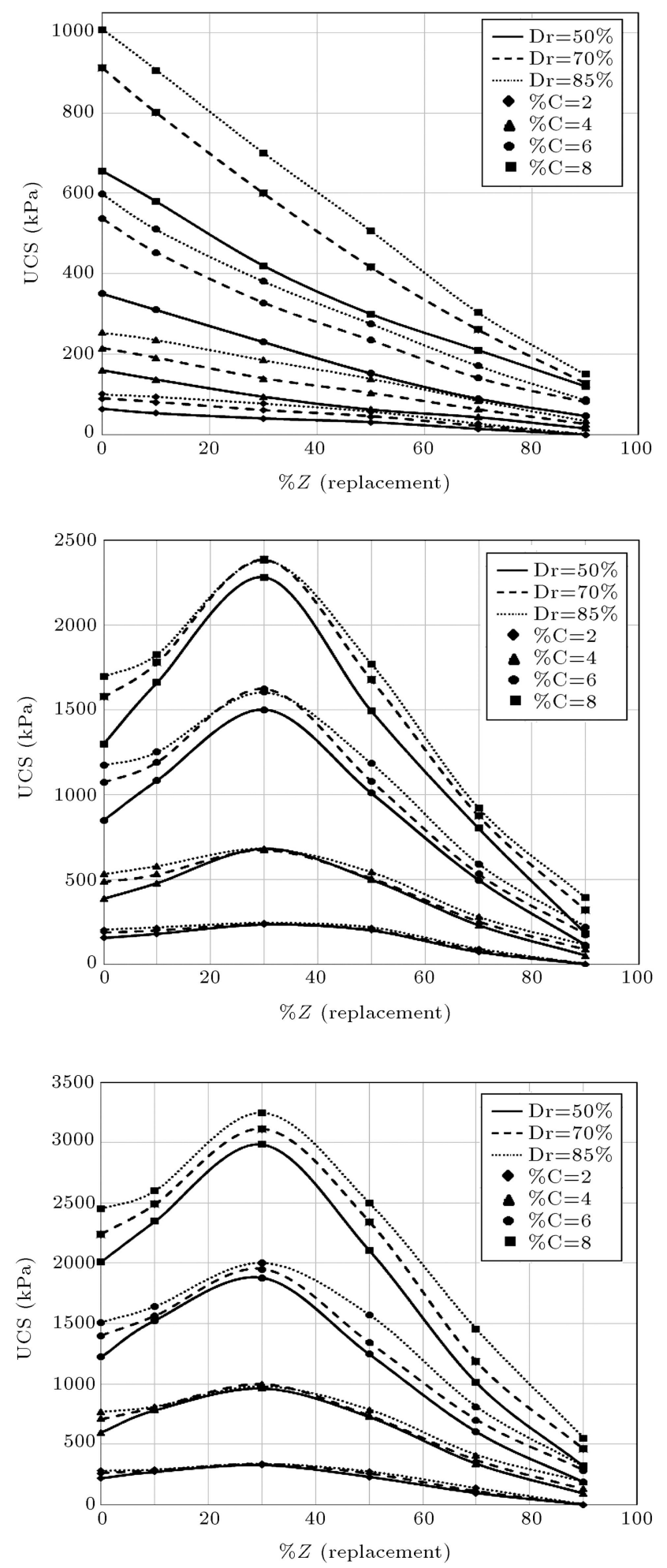

Figure 3. Effect of additive materials to sand via UCS.

different relative densities at the zeolite content of $30 \%$. This rate of increase is more evident at higher cement contents and lower relative densities due to higher amounts of zeolite-cement hydration products. Therefore, adding zeolite can affect the strength of cemented sand considerably.
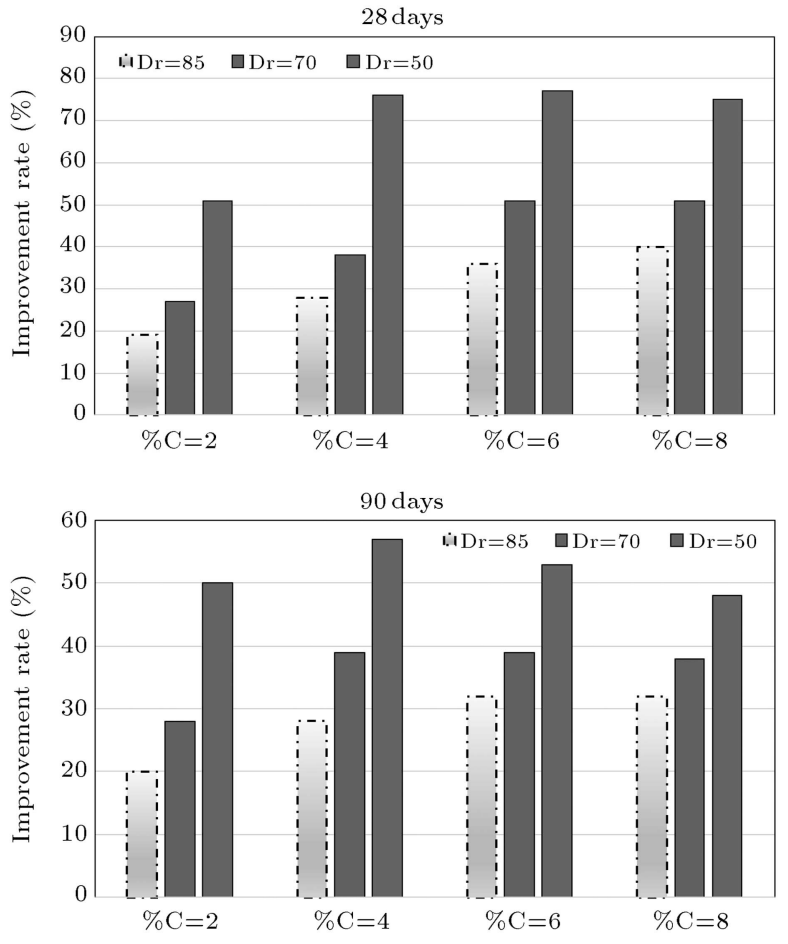

Figure 4. UCS improvement of cemented sand replaced by optimum value of zeolite.

\subsection{Porosity effect}

Figure 5 shows the effects of porosity, $n$, on the peak strength of zeolite cemented sand (up to $50 \%$ cement replacement). UCS reduced with the increases in porosity of both zeolite and cement samples. The loss of strength rate is more for cemented mixtures and samples cured in 7 days; the loss of strength rate for 28 and 90 days of curing times of zeolite cemented samples is relatively minor. In other words, when cement is replaced by optimum zeolite $(30 \%)$, the variation of UCS is approximately constant by increasing porosity. Therefore, the effectiveness of using zeolite instead of cement is greater in more porosity blends.

\subsection{Curing time effects}

The variation of curing time affects the UCS of zeolite cemented sand mixtures presented in Figure 6 (up to $50 \%$ cement replacement). As one can see, Figure 6 shows that by increasing curing time, UCS increases with decreasing rate.

\subsection{Evaluation of UCS using polynomial model}

One of the main objective of this research is to develop a polynomial function of input zeolite-cemented sand parameters to estimate the USC as output. It can be seen from Figures 3 that for zeolite-cemented materials, the UCS behave approximately polynomially with the increase in the zeolite content. As presented in Table 2, polynomial formulas based on Voltra series are one of the best fits, where $C$ and $Z$ are the cement and 

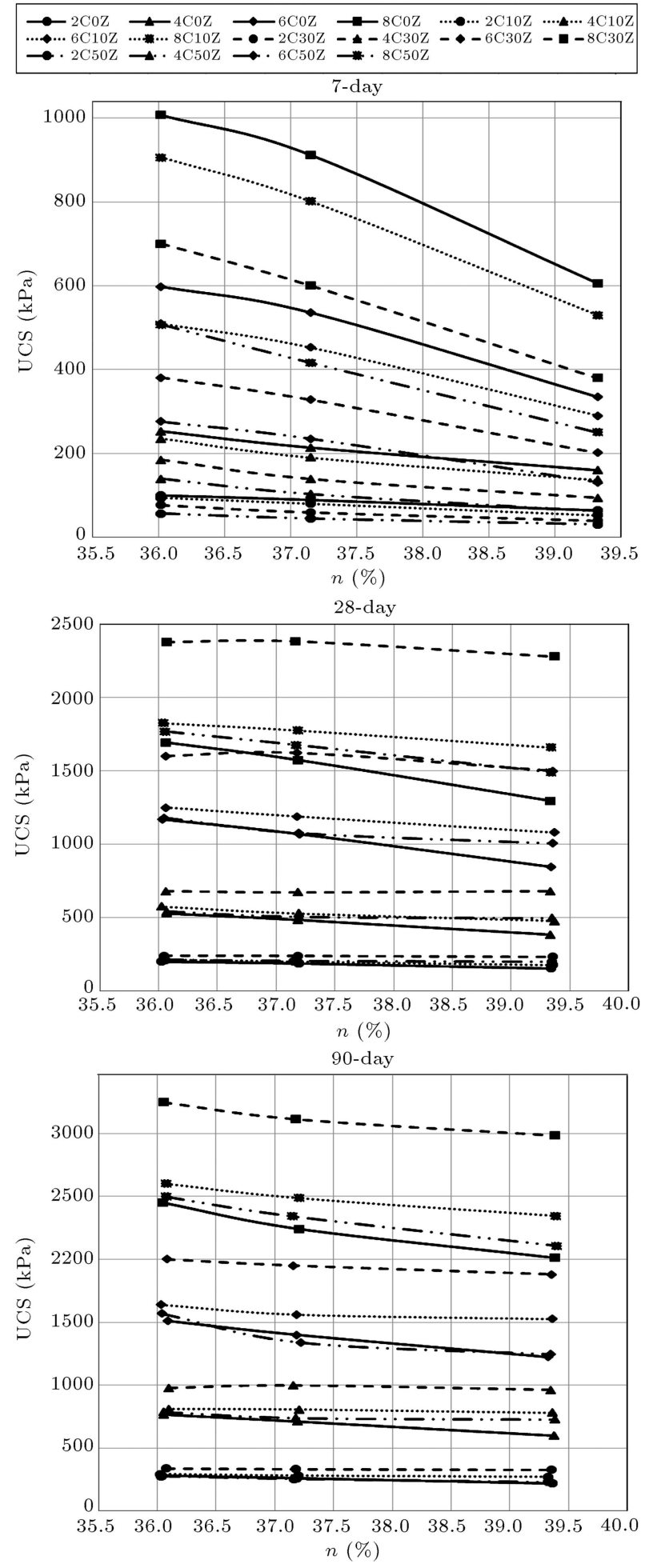

Figure 5. UCS variations through porosity for cement-zeolite samples after 7, 28, and 90 days.

zeolite percentages of $100 \mathrm{~g}$ total dry soil. At high dry densities (more compacted mixtures), there are many more contacts between the products of the cement hydration and soil particles, and so the effectiveness of the cement is greater.
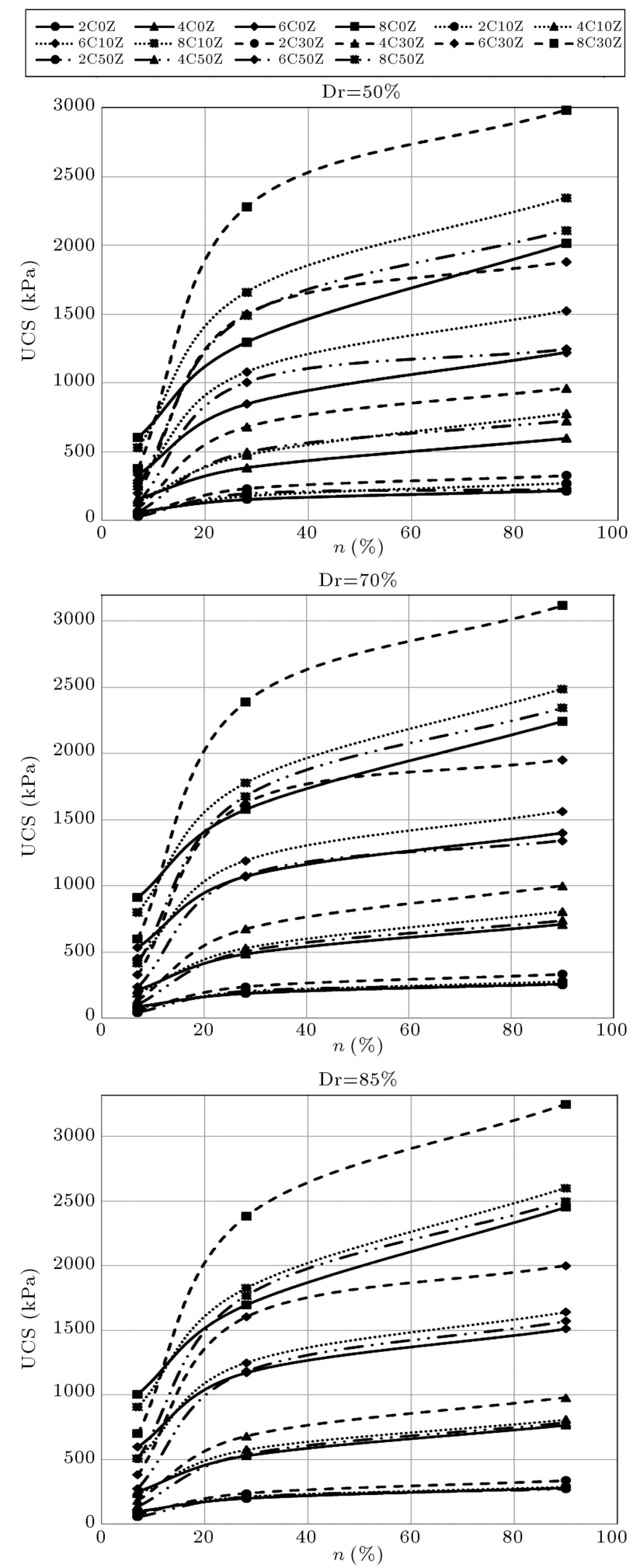

Figure 6. UCS variations with curing time for cement-zeolite samples with different relative densities.

\subsubsection{Effect of porosity}

As shown in Figure 5, there exists a relationship between the UCS and the porosity adjusted by polynomial function for the zeolite cemented soil mixtures. 
Table 2. Polynomial correlations for predicting UCS.

\begin{tabular}{cccc}
\hline $\begin{array}{c}\text { Curing time } \\
(\text { day })\end{array}$ & Dr $(\%)$ & Correlations & $\boldsymbol{R}$ \\
\hline \multirow{2}{*}{7} & 85 & UCS $(\mathrm{kPa})=-194+139 \mathrm{C}+62 \mathrm{Z}-4 \mathrm{Z}^{2}-4 \mathrm{CZ}$ & 0.977 \\
& 70 & $\mathrm{UCS}(\mathrm{kPa})=-208.5+132 \mathrm{C}+70 \mathrm{Z}-5 \mathrm{Z}^{2}-9 \mathrm{CZ}$ & 0.973 \\
& 50 & $\mathrm{UCS}(\mathrm{kPa})=-111+81 \mathrm{C}+32 \mathrm{Z}-\mathrm{Z}^{2}-5 \mathrm{CZ}$ & 0.974 \\
\hline \multirow{2}{*}{28} & 85 & $\mathrm{UCS}(\mathrm{kPa})=-286+244 \mathrm{C}+112 \mathrm{Z}-16 \mathrm{Z}^{2}+60 \mathrm{CZ}$ & 0.979 \\
& 70 & $\mathrm{UCS}(\mathrm{kPa})=-269+229 \mathrm{C}+101 \mathrm{Z}-17 \mathrm{Z}^{2}+63 \mathrm{CZ}$ & 0.973 \\
& 50 & $\mathrm{UCS}(\mathrm{kPa})=-231+195 \mathrm{C}+98 \mathrm{Z}-20 \mathrm{Z}^{2}+67 \mathrm{CZ}$ & 0.970 \\
\hline \multirow{2}{*}{90} & 85 & $\mathrm{UCS}(\mathrm{kPa})=-395+337 \mathrm{C}+147 \mathrm{Z}-20 \mathrm{Z}^{2}+83 \mathrm{CZ}$ & 0.974 \\
& 70 & $\mathrm{UCS}(\mathrm{kPa})=-356+315 \mathrm{C}+130 \mathrm{Z}-20 \mathrm{Z}^{2}+78 \mathrm{CZ}$ & 0.959 \\
& 50 & $\mathrm{UCS}(\mathrm{kPa})=-330+290 \mathrm{C}+131 \mathrm{Z}-24 \mathrm{Z}^{2}+77 \mathrm{CZ}$ & 0.955 \\
\hline
\end{tabular}

It can be seen that the rates of change of UCS with porosity for 7-day curing time and after 28-day curing time are substantially different. One way to make the variation rates of porosity compatible is through the application of polynomial model (voltra series) to previous polynomial model of them. It was found that for the relationship between UCS and porosity, the optimum fit could be obtained by applying polynomial models as shown in Table 3, with its performance available in Figure 7; in Table 3, where $C$ and $Z$ are the cement and zeolite percentages of $100 \mathrm{~g}$ total dry soil with porosity $(n)$ in percent.

\subsubsection{Effect of curing time}

The effects of curing time on the UCS of the zeolite cement soil are shown in Figure 6. As shown in Figure 6 , with the increase of curing time, UCS increases polynomially with decreasing rate. Therefore, polynomial function can well estimate the relation between UCS and curing time of both zeolite and cemented soil specimens with a different porosity (Figure 8). The corresponding polynomial representation of such a model for UCS is as follows:

$$
\begin{aligned}
\mathrm{UCS}= & -317.5+0.48 Y_{2}+25.01 d+0.0001 Y_{2}^{2} \\
& -0.24 d^{2}+0.012 d . Y_{2},
\end{aligned}
$$

$$
\begin{aligned}
Y_{2}= & 0.5+1.7 Y_{1}+9.55 n+0.0001 Y_{1}^{2}-0.221 n^{2} \\
& -0.025 n . Y_{1}, \\
Y_{1}= & -19.9+70.1 C+15.5 Z+16.23 C^{2}-7.56 Z^{2} \\
& +60.7 C . Z
\end{aligned}
$$

where $C$ and $Z$ are the cement and zeolite percentages of $100 \mathrm{~g}$ total dry soil with porosity $(n)$ in different curing times $(d)$.

\subsubsection{Performance of polynomial models}

The structure of the evolved polynomial models is shown in Figure 9 corresponding to the input representations for different conditions such as the effect of zeolite, porosity, and curing time.

The polynomial models show one of the best correlations by assuming different conditions, and the proposed equation results in points more closely located around the 1:1 line. It can be seen that the polynomial models could successfully model and predict the output of testing data that have not been tested.

Absolute fraction of variance $\left(R^{2}\right)$, Root Mean Squared Error (RMSE), Mean Absolute Percent Error (MAPE), and Mean Absolute Deviation (MAD) are used to evaluate the performance of the proposed

Table 3. Polynomial correlations for predicting UCS considering porosity.

\begin{tabular}{cl}
$\begin{array}{c}\text { Curing time } \\
\text { (day) }\end{array}$ & \multicolumn{1}{c}{ Correlations } \\
\hline \multirow{2}{*}{7} & $\mathrm{UCS}=0.17+7.43 Y_{1}+3.15 n+0.0000064 Y_{1}^{2}-0.81 n^{2}-0.17 n . Y_{1}$ \\
& $Y_{1}=47.9-13.98 C-20.57 Z+14.23 C^{2}+2.97 Z^{2}+12.81 C . Z$ \\
\hline \multirow{2}{*}{28} & $\mathrm{UCS}=0.95+1.84 Y_{1}+17.27 n+0.0004 Y_{1}^{2}-0.41 n^{2}-0.03 n . Y_{1}$ \\
& $Y_{1}=-83.4+141.6 C+42.9 Z+12.02 C^{2}-13.1 Z^{2}+78.8 C . Z$ \\
\hline \multirow{2}{*}{90} & $\mathrm{UCS}=0.97+2.02 Y_{1}+18.3 n+0.0001 Y_{1}^{2}-0.421 n^{2}-0.03 n . Y_{1}$ \\
& $Y_{1}=-24.3+110.3 C+24.1 Z+22.45 C^{2}-12.6 Z^{2}+108.4 C . Z$ \\
\hline
\end{tabular}



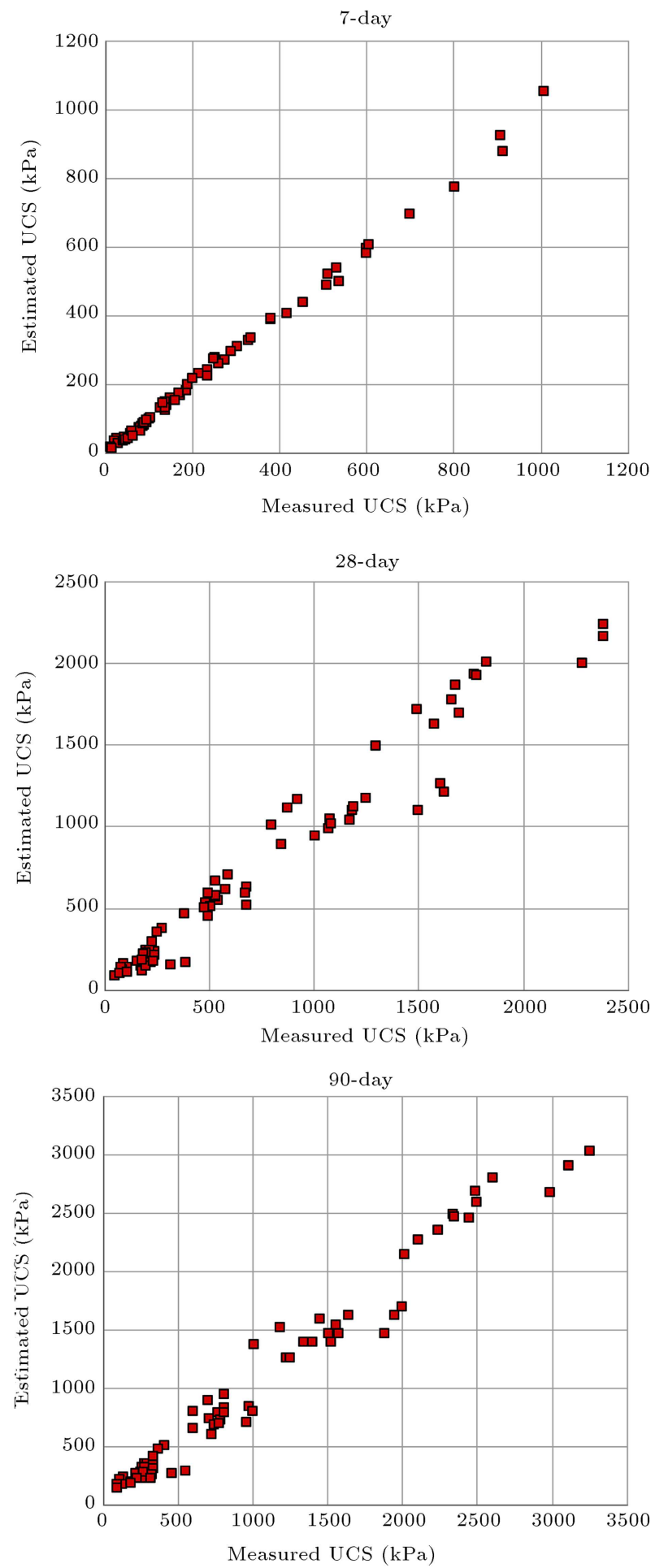

Figure 7. The measured UCS obtained from the unconfined compression test versus polynomial model output for different curing times.

equations and models, which are defined as follows:

$$
R^{2}=1-\left[\frac{\sum_{1}^{M}\left(C_{m i}-C_{p i}\right)^{2}}{\sum_{1}^{M}\left(C_{m i}\right)^{2}}\right],
$$

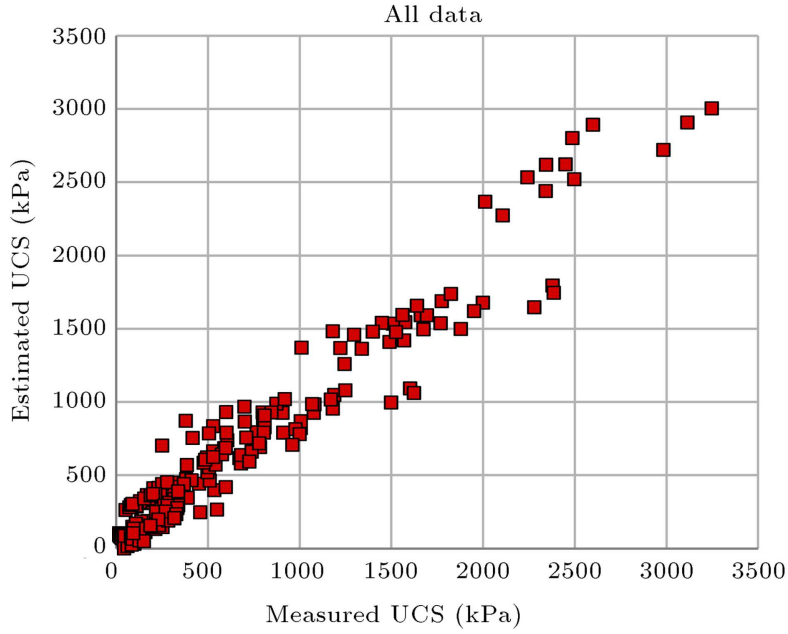

Figure 8. The measured UCS obtained from the unconfined compression test versus polynomial model output.

\begin{tabular}{|c|l|l|}
\hline Effect of zeolite & Effect of porosity & Effect of curing time \\
\hline Zement & UClite & $\begin{array}{l}\text { Cement } \\
\text { Zeolite }\end{array} Y_{Y_{1}}$ \\
Porosity & Curing time \\
\hline
\end{tabular}

Figure 9. Evolved structure of generalized polynomial models.

$$
\begin{aligned}
& \text { RMSE }=\sqrt{\frac{1}{M} \sum_{1}^{M}\left(C_{m i}-C_{p i}\right)^{2},} \\
& \text { MAPE }=\frac{\sum_{1}^{M}\left|C_{m i}-C_{p i}\right|}{\sum_{1}^{M} C_{m i}} \times 100, \\
& \text { MAD }=\frac{\sum_{1}^{M}\left|C_{m i}-C_{p i}\right|}{M},
\end{aligned}
$$

where $C_{m i}$ and $C_{p i}$ are the measured and predicted UCS. The lower the values of the RMSE, MAPE, and MAD are, the better the model performance will be. Under ideal conditions, an accurate and precise method gives $R^{2}$ of 1.0, RMSE, MAPE, and MAD of 0 .

In Table 4, the values of RMSE, MAPE, and MAD are found for the polynomial model in different condition stages.

On the other hand, for cemented sand, a power function can fit as the relation between UCS and porosity $(n)$ of cemented soil specimens as voids/volumetric cement content ratio $\left(\frac{n}{C v}\right)$ parameter that has been investigated by several researchers. In this part, based on only the cemented sand samples, parameters of voids/cement model are adjusted and compared to this 

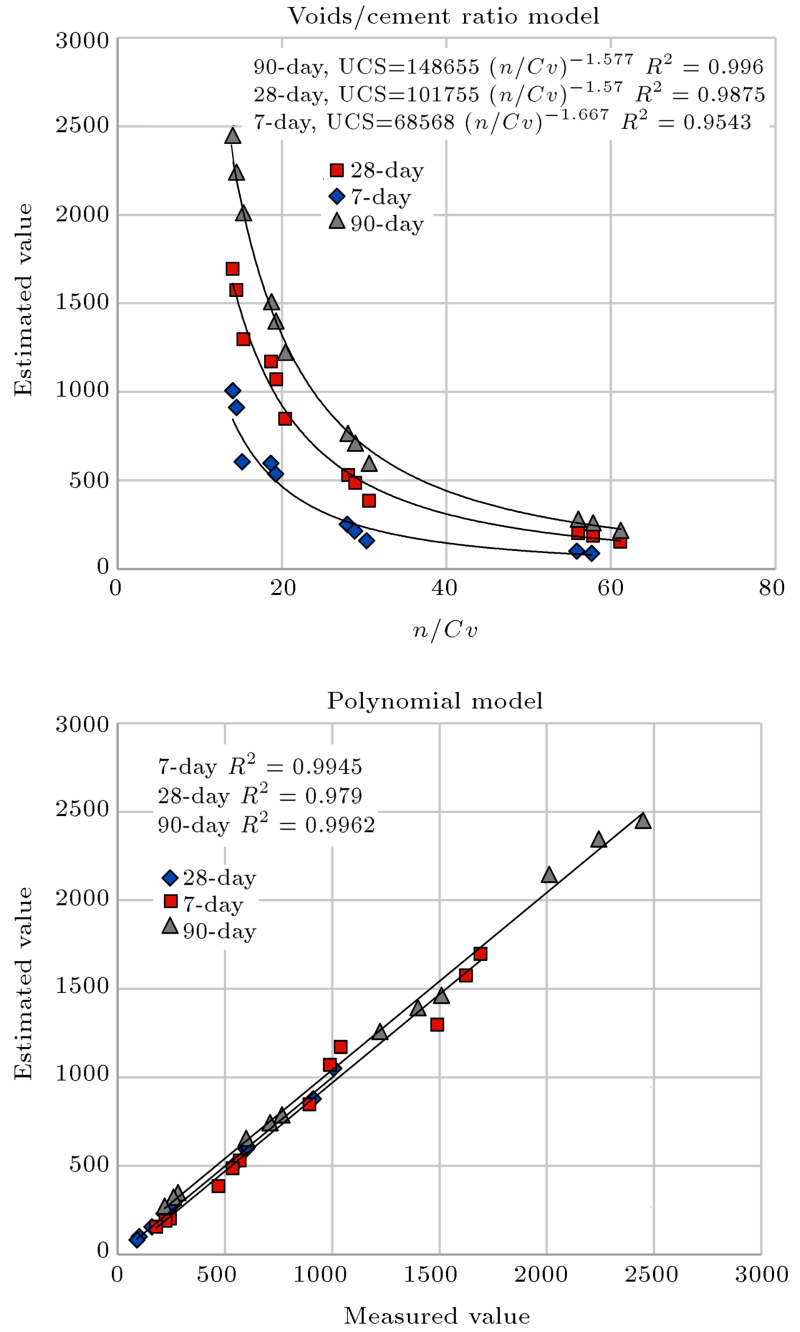

Figure 10. Adjusted voids/cement ratio and polynomial model for cemented specimens.

study's correlations (equations presented in Table 3 with value of zeolite $=0$ ) as in Figure 10. As shown in Figure 10, the predictability of the polynomial model is satisfactory in comparison with the voids/cement ratio model.

\subsubsection{Sensitivity analysis}

Because the polynomial model produced by Eq. (11) is in the form of complex equations; thus, the effect of input parameters on the model output is not clearly evident. The sensitivity analysis of the obtained model is carried out to evaluate the influence of the input parameters on the model output. The sensitivity

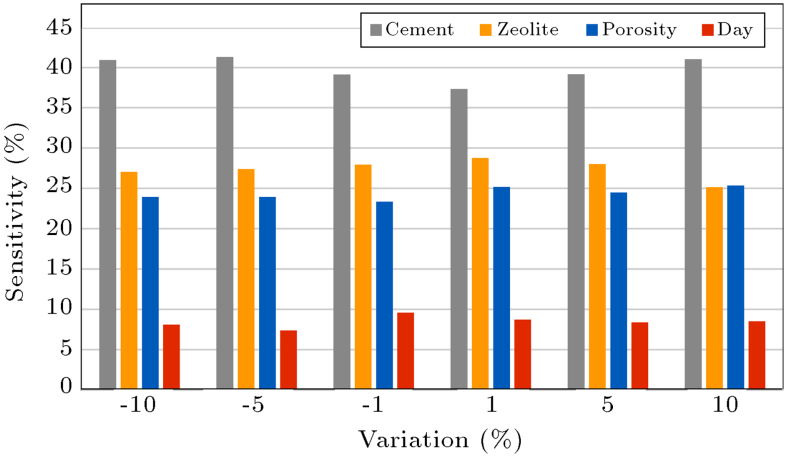

Figure 11. Results of the sensitivity analysis of the obtained model for UCS.

test is carried out by varying each of the normalized input at a constant rate, one at a time, while other variables are constant. Various constant rates $(0.9$, $0.95,0.99, \ldots, 1.1)$ are selected in the study. For every input parameter, the percentage change in the output is observed as a result of the change in the input parameter. The sensitivity of each input parameter is calculated by the following equation [34]:

$$
\begin{aligned}
& \text { Sensivity level of } X_{i}(\%)= \\
& \qquad \frac{1}{M} \sum_{j=1}^{M}\left(\frac{\% \text { change in output }}{\% \text { change in input }}\right)_{j} \times 100
\end{aligned}
$$

Results of the sensitivity analysis of the obtained model are shown in Figure 11. It can be noticed from this figure that the UCS is considerably influenced by the cement content. Also, curing time has little effect on the correlation.

The results presented in this paper, therefore, suggest that an engineer can choose the appropriate amount of cement, zeolite, and compaction energy to provide a mixture that meets the strength required by the project at the optimum cost using polynomial model as represented by voltra series for given characteristics, percentage, and curing time. The polynomial models can also be useful in the field control of zeolite in soil-cement layers. Once a poor compaction has been identified, through these study models, one can readily take account of the design and corrective measure adoption, accordingly, such as the zeolite of the treated layer or the reduction in the load transmitted. It is important to make clear that the trends observed

Table 4. Statistical results for polynomial correlations.

\begin{tabular}{cccccc}
\hline Equation & & $\boldsymbol{R}^{\mathbf{2}}$ & MAPE & RMSE & MAD \\
\hline \multirow{3}{*}{ Include porosity } & 7 days & 0.999 & 12.83 & 3.87 & 9.24 \\
& 28 days & 0.981 & 14.7 & 12.97 & 10.9 \\
& 90 days & 0.988 & 13.51 & 10.5 & $\mathbf{9 . 8}$ \\
Include curing time & & 0.968 & 18.69 & 17.5 & 12.7 \\
\hline
\end{tabular}


herein are relevant to the soil, cement, and zeolite type and content used in the present research, and that further studies are necessary to generalize such findings.

\section{Conclusions}

The zeolite insertion causes an increase in unconfined compression strength in the cemented soil (for the whole range of cement studied).

Other remarks of the paper are:

- The addition of cement, even in small amounts, greatly improved the soil strength of zeolite cement and cemented soils. For the cement contents studied here, the unconfined compression strength increased approximately linearly with the increase in the cement content; for the cement replaced by zeolite samples, UCS increased and decreased through zeolite replacement with polynomial correlations. The optimum value of zeolite for all cement contents was $30 \%$ which improved UCS 20 to $80 \%$ and 20 to $60 \%$ for 28 -day and 90 -day samples, respectively. The rate of strength gain, represented by Figure 5, increased with the decrease in the dry density and the increase in cement content. It is indicated that the effectiveness of the zeolite is greater in more cemented and less compacted mixtures;

- The decrease in the porosity of the compacted mixture greatly improved the strength for the cemented soils and slightly improved the strength for zeolite cement mixtures. It is shown that the unconfined compressive strength increases in power model with the reduction in the porosity of the compacted mixture;

- The polynomial models, defined by cement and zeolite contents, porosity of the compacted mixture, and curing time have been shown to be a more appropriate model to evaluate the unconfined compression strength of zeolite soil-cement mixtures studied;

- The developed polynomial model proved to be more efficient than previous correlations, and cement content appeared to be the most influential on the UCS value.

\section{References}

1. Clough, G.W., Rad, N.S., Bachus, R.C. and Sitar, N. "Cemented sands under static loading", Journal of the Geotechnical Engineering Division, 107(6), pp. 799817 (1981).

2. Coop, M.R. and Atkinson, J.H. "The mechanics of cemented carbonate sands", Geotechnique, 43(1), pp. 53-67 (1993).
3. Consoli, N.C., Rotta, G.V. and Prietto, P.D.M. "The influence of curing under stress on the triaxial response of cemented soils", Geotechnique, 50(1), pp. 99-105 (2000).

4. Consoli, N.C., Rotta, G.V. and Prietto, P.D.M. "Yielding-compressibility-strength relationship for an artificially cemented soil cured under stress", Geotechnique, 56(1), pp. 69-72 (2006).

5. Consoli, N.C., Foppa, D., Festugato, L. and Heineck, K.S. "Key parameters for strength control of artificially cemented soils", Journal of Geotechnical and Geoenvironmental Engineering, ASCE, 133(2), pp. 197-205 (2007).

6. Consoli, N.C., Lopes Jr., L.S., Foppa, D. and Heineck, K.S. "Key parameters dictating strength of lime/cement-treated soil", Proceedings of the Institution of Civil Engineers-Geotechnical Engineering, 162(2), pp. 111-118 (2009).

7. Consoli, N.C., Lopes Jr., L.S. and Heineck, K.S. "Key parameters for the strength control of lime stabilized soils", Journal of Materials in Civil Engineering, 21(5), pp. 210-216 (2009).

8. Consoli, N.C., Festugato, L., da Rocha, C.G. and Cruz, R.C. "Key parameters for strength control of rammed sand-cement mixtures: Influence of types of Portland cement", Construction and Building Materials, 49, pp. 591-597 (2013).

9. Consoli, N.C. and Foppa, D. "Porosity/cement ratio controlling initial bulk modulus and incremental yield stress of an artificially cemented soil cured under stress", Géotechnique Letters, 4(1), pp. 22-26 (2014).

10. Thomé, A., Donato, M., Consoli, N.C. and Graham, J. "Circular footings on a cemented layer above weak foundation soil", Canadian Geotechnical Journal, 42, pp. 1569-1584 (2005).

11. Dalla Rosa, F., Consoli, N.C. and Baudet, B.A. "An experimental investigation of the behaviour of artificially cemented soil cured under stress", Geotechnique, 58(8), pp. 675-679 (2008).

12. Horpibulsuk, S., Suddeepong, A., Suksiripattanapong, C., Chinkulkijniwat, A., Arulrajah, A. and Disfani, M.M. "Water-void to cement ratio identity of lightweight cellular-cemented material", Journal of Materials in Civil Engineering, 26(10), pp. 263-275 (2014).

13. Faro, V.P., Consoli, N.C., Schnaid, F., Thomé, A. and da Silva Lopes, L. "Field tests on laterally loaded rigid piles in cement treated soils", Journal of Geotechnical and Geoenvironmental Engineering, 141(6), pp. 605615 (2015).

14. Yilmaz, E., Belem, T. and Benzaazoua, M. "Specimen size effect on strength behavior of cemented paste backfills subjected to different placement conditions", Engineering Geology, 185, pp. 52-62 (2015).

15. Choobbasti, A.J., Vafaei, A. and Kutanaei, S.S. "Mechanical properties of sandy soil improved with cement and nanosilica", Open Engineering, 5(1), pp. 97-103 (2015). 
16. Arabani, M., Sharafi, H., Habibi, M.R. and Haghshenas, E. "Laboratory evaluation of cement stabilized crushed glass-sand blends", Electronic Journal of Geotechnical Engineering, 17, pp. 1777-1792 (2015).

17. Pino, L.F.M. and Baudet, B.A. "The effect of the particle size distribution on the mechanics of fibrereinforced sands under one-dimensional compression", Geotextiles and Geomembranes, 43(3), pp. 250-258 (2015).

18. Consoli, N.C., Prietto, P.D.M. and Ulbrich, L.A. "Influence of fiber and cement addition on behavior of sandy soil", Journal of Geotechnical and Geoenvironmental Engineering, 124(12), pp. 1211-1214 (1998).

19. Consoli, N.C., Vendruscolo, M.A., Fonini, A. and Dalla Rosa, F. "Fiber reinforcement effects on sand considering a wide cementation range", Geotextiles and Geomembranes, 27(3), pp. 196-203 (2009).

20. Consoli, N.C., Consoli, B.S. and Festugato, L. "A practical methodology for the determination of failure envelopes of fiber-reinforced cemented sands", Geotextiles and Geomembranes, 41, pp. 50-54 (2013).

21. Poon, C.S., Lam, L., Kou, S.C. and Lin, Z.S. "A Study on the hydration rate of natural zeolite blended cement pastes", Construction and Building Materials, 13, pp. 427-432 (1999).

22. Perraki, T, Kakali, G. and Kontoleon, F. "The effect of natural zeolites on the early hydration of Portland cement", Microporous and Mesoporous Materials, 61, pp. 205-212 (2003).

23. Feng, N.Q., Li, Z.G., and Zang, X.W. "High strength and flowing concrete with a zeolite mineral admixture", Cement and Concrete Aggregate, ASTM, 12, pp. 61-69 (1990).

24. Canpolat, F., Yilmaz, K., Mkose, M., Sumer, M. and Yurdusev, M.A. "Use of zeolite, coal bottom ash and fly ash as replacement materials in cement production", Cement and Concrete Research, 34, pp. 731-735 (2004).

25. Yılmaz, B., Ucar, A., Oteyaka, B. and Uz, V. "Properties of zeolitic tuff (clinoptilolite) blended portland cement", Building and Environment, 42, pp. 3808-3815 (2007).

26. ASTM D-421, Standard Practice for Dry Preparation of Soil Samples for Particle-Size Analysis and Determination of Soil Constan, Annual Book of ASTM Standards, American Society for Testing and Materials, West Conshohocken, pp. 1-2 (2012).

27. ASTM D-422, Standard Test Method for Particle-Size Analysis of Soils, American Society for Testing and Materials, West Conshohocken, pp. 1-2 (2012).

28. ASTM D-2166, Standard Test Method for Unconfined Compressive Strength of Cohesive Soil, Annual Book of ASTM Standards, American Society for Testing and Materials, West Conshohocken., pp. 1-6 (2000).

29. Kalantary, F., Ardalan, H. and Nariman-Zadeh, N. "An investigation on the S u-N SPT correlation using GMDH type neural networks and genetic algorithms", Engineering Geology, 104(1), pp. 144-155 (2009).

30. Ardalan, H., Eslami, A. and Nariman-Zadeh, N. "Piles shaft capacity from CPT and CPTu data by polynomial neural networks and genetic algorithms", Computers and Geotechnics, 36(4), pp. 616-625 (2009).

31. Mola-Abasi, H., Dikmen, U. and Shooshpasha, I. "Prediction of shear wave velocity from CPT data at Eskisehir (Turkey), using a polynomial model", Near Surface Geophysics, 13(2), pp.155-167 (2015).

32. Kordnaeij, A., Kalantary, F., Kordtabar, B. and MolaAbasi, H. "Prediction of recompression index using GMDH-type neural network based on geotechnical soil properties", Soils and Foundations, 55(6), pp. 13351345 (2015). DOI: 10.1016/j.sandf.2015.10.001

33. Jamali, A., Nariman-zadeh, N., Darvizeh, A., Masoumi, A. and Hamrang, S. "Multi-objective evolutionary optimization of polynomial neural networks for modelling and prediction of explosive cutting process", Engineering Applications of Artificial Intelligence, 22, pp. 676-687 (2008).

34. Liong, S.Y., Lim, W.H. and Paudyal, G.N. "River stage forecasting in Bangladesh: neural network approach", Journal of Computing in Civil Engineering, 14, pp. 1-8 (2000).

\section{Biographies}

Hossein Mola-Abasi received his $\mathrm{MSc}$ and $\mathrm{PhD}$ degrees in Geotechnical Engineering from the University of Guilan, in 2010, and Babol University of Technology, in 2016, respectively. $\mathrm{He}$ is currently Assistant Professor in Gonbad University. His research interests are mainly in the area of soft computing in geomechanics, with special focus on earthquake geotechnical engineering and dynamic behavior of soils, and more recently on soil improvement techniques.

Issa Shooshpasha is an Associate Professor in the Faculty of Civil Engineering in Babol University of Technology. He received his BSc degree in Tabriz University in 1987, his MSc and PhD degrees at McGill University in 1993 and 1996, respectively. His research interests are mainly in the area of bearing capacity of shallow and deep foundations, slope stability, liquefaction, and soil improvement. 